\title{
Is the fusion order of the cranial and caudal levels different in two-level anterior cervical discectomy and fusion for cervical spondylopathy? A retrospective study
}

\author{
Xia-Qing Sheng ${ }^{1}$, Yang Meng ${ }^{1}$, Hao Liu ${ }^{1 *}$, Bei-Yu Wang ${ }^{1}$, Yi Yang ${ }^{1}$, Xin Rong ${ }^{1}$ and Ying Hong ${ }^{2,3}$
}

\begin{abstract}
Study design: Retrospective study.

Objective: This study aimed to compare the fusion order between the cranial and caudal levels in two-level anterior cervical discectomy and fusion (ACDF) with a zero-profile device in the treatment of cervical spondylopathy.
\end{abstract}

Summary of background data: Fusion is the standard used to judge the success of ACDF. However, the fusion order in two-level ACDF remains uncertain. The mechanical environment of different levels is different, which may affect the fusion rate or fusion order.

Methods: From 2014 to January 2019, data of consecutive patients with two-level cervical disk degenerative disease who underwent ACDF were retrospectively reviewed. Radiological assessments were based on the range of motion of the fusion level, segment slope, and disk height, and complications were assessed. Data were analyzed using the paired $t$, Mann-Whitney $U, X^{2}$, Fisher exact, and rank-sum tests and logistic regression analysis.

Results: In total, 118 patients were ultimately enrolled for analysis in the study. The respective fusion rates of the cranial and caudal levels were $26.27 \%$ and $10.17 \%(p<0.05)$ at 3 months, $58.47 \%$ and $42.37 \%(p<0.05)$ at 6 months, $86.44 \%$ and $82.20 \%$ ( 10.05 ) at 1 year, and $92.37 \%$ and $89.83 \%$ ( $p>0.05$ ) at the last follow-up. Multivariate logistic regression analysis indicated that the preoperative segmental slope and cranial level were independent risk factors for non-fusion. The adjacent segment degeneration (ASD) and subsidence rates were comparable between the two levels.

Conclusion: The caudal level had a slower fusion process than the cranial level. A higher preoperative segment slope was a risk factor for fusion. However, the subsidence and ASD rate were comparable between the caudal and cranial levels in the two-level ACDF.

Keywords: Cervical, Anterior cervical discectomy and fusion, Fusion order, Zero-profile device, Segment slope, Cranial and caudal levels

\footnotetext{
* Correspondence: dr.liuhao6304@yahoo.com

'Department of Orthopedic Surgery, West China Hospital, Sichuan University, No. 37 Guo Xue Xiang, Chengdu 610041, Sichuan, China

Full list of author information is available at the end of the article
}

(c) The Author(s). 2021 Open Access This article is licensed under a Creative Commons Attribution 4.0 International License, which permits use, sharing, adaptation, distribution and reproduction in any medium or format, as long as you give appropriate credit to the original author(s) and the source, provide a link to the Creative Commons licence, and indicate if changes were made. The images or other third party material in this article are included in the article's Creative Commons licence, unless indicated otherwise in a credit line to the material. If material is not included in the article's Creative Commons licence and your intended use is not permitted by statutory regulation or exceeds the permitted use, you will need to obtain permission directly from the copyright holder. To view a copy of this licence, visit http://creativecommons.org/licenses/by/4.0/. The Creative Commons Public Domain Dedication waiver (http://creativecommons.org/publicdomain/zero/1.0/) applies to the data made available in this article, unless otherwise stated in a credit line to the data. 


\section{Introduction}

Anterior cervical discectomy and fusion (ACDF) is a classic procedure for treating cervical spondylosis with good clinical outcomes and improves patient's quality of life [1-5]. The success of ACDF relies on the achievement of arthrodesis. Although pseudarthrosis can often be asymptomatic, it may finally lead to mechanical pain, poor patient satisfaction, and implant failure requiring revision [6-8]. In the presence of these clinical problems, it is imperative to go back to basic research, analyze the causes of the problems, and propose solutions so as to guide clinical practice again, which is in line with the model of translational medicine [9].

In previous studies, the fusion rate of two-level ACDF varied; a systematic review [10] reported a mean fusion rate of $90.1 \%$, which ranged from 30 to $100 \%$. Smoking, osteoporosis, diabetes, preoperative range of motion (ROM), and preoperative $\mathrm{T} 1$ slope are the factors that influence the fusion rate or fusion speed [11-16].

In addition, different spine levels have unequal mechanical environments, which may lead to a discrepancy in the fusion process among levels. A few studies have found that pseudarthroses often appear at the caudal level in multi-level ACDF $[17,18]$. However, the fusion order in two-level ACDF is rarely known. Therefore, this study aimed to explore the fusion rate and fusion order between the cranial and caudal levels in two-level ACDF for cervical spondylosis. The hypothesis was that the caudal level has a slower fusion process than the cranial level, according to which an improved strategy of bone graft could be made.

\section{Materials and methods}

\section{Study design and patient population}

This retrospective study was conducted from January 2014 to January 2019. The study protocol was approved by the Ethics Committee on Biomedical Research of the West China Hospital of Sichuan University, and informed consent was obtained from the patients. In total, 129 consecutive inpatients from a single center had undergone two-level ACDF with failed conservative treatment for at least 6 weeks. Surgical indications were symptomatic radiculopathy and/or myelopathy caused by contiguous two-level cervical degenerative disk disease between $\mathrm{C} 2$ and $\mathrm{C} 7$ based on clinical performance, preoperative radiography, computed tomography (CT), and magnetic resonance imaging (MRI) findings. The exclusion criteria were (1) a history of cervical spine surgery and (2) other cervical diseases including infection, cervical spinal tumor, cervical fracture, or other severe systematic diseases.

\section{Surgical techniques}

In our hospital, all procedures were performed by a single surgeon with a standard right-side anterior approach after general anesthesia. A transverse incision was made along the skin on the right and front of the patient's neck. Complete discectomy was conducted at the indicated levels by removing the disk tissue, posterior longitudinal ligament, and osteophytes to achieve thorough decompression. A high-speed burr was used to prepare the endplates, and a properly sized Zero-P implant (Synthes, Oberdorf, Switzerland) filled with a composite synthetic bone graft (beta-tricalcium phosphate, ChronOS; DePuy Synthes, Paoli, CA, USA) was inserted into the indicated levels. Proper placement of the implants was verified by $\mathrm{C}$-arm fluoroscopy. Finally, the muscle was closed with sutures, and the subcutaneous tissue and skin were then sutured layer by layer after drainage insertion. Recombinant human bone morphogenetic protein-2 (rhBMP-2) was not used concurrently. All patients wore neck braces for 3 months.

\section{Radiological parameters}

Radiographical outcomes were measured before surgery; at 1 week, 3 months, 6 months, and 1 year after surgery; and at the last follow-up. Radiological parameters included disk height (DH), ROM of the fusion level, and segment slope. Adjacent segment degeneration (ASD) was defined as a progressive or new-onset posterior osteophyte, decrease in $\mathrm{DH}>25 \%$, disk herniation, disk signal change, or anterior/posterior longitudinal ligament calcification at the final follow-up compared with the preoperative state on lateral radiographs or MRI scans [19]. Fusion was defined as ROM of the fusion level $<2^{\circ}$ on lateral flexion/extension radiographs and the presence of trabecular bridging on radiographs or CT scans $[10,20]$. Subsidence was defined as DH loss > $2 \mathrm{~mm}$ from 1 week to the last follow-up postoperatively. The segment slope was defined as the angle between the horizontal line and the extension line of the upper endplate of the middle (or caudal) vertebral body (Fig. 1). PACS version 4.0 (GE Healthcare, Milwaukee, WI, USA) was used to measure the radiological parameters.

\section{Statistical analysis}

The results are presented as the mean \pm standard deviation. A paired $t$ test was used to analyze normally distributed contiguous data between the cranial and caudal levels, and the Mann-Whitney $U$ test was used to analyze non-normally distributed data. The $\chi^{2}$ test and Fisher exact test were used to analyze categorical data. The ranksum test was used to determine the difference of the fusion rate at $\mathrm{C} 3-\mathrm{C} 7$ absolute positions. Logistic regression analysis was used to identify risk factors for non-fusion. SPSS software version 23.0 (IBM Corporation, Armonk, 


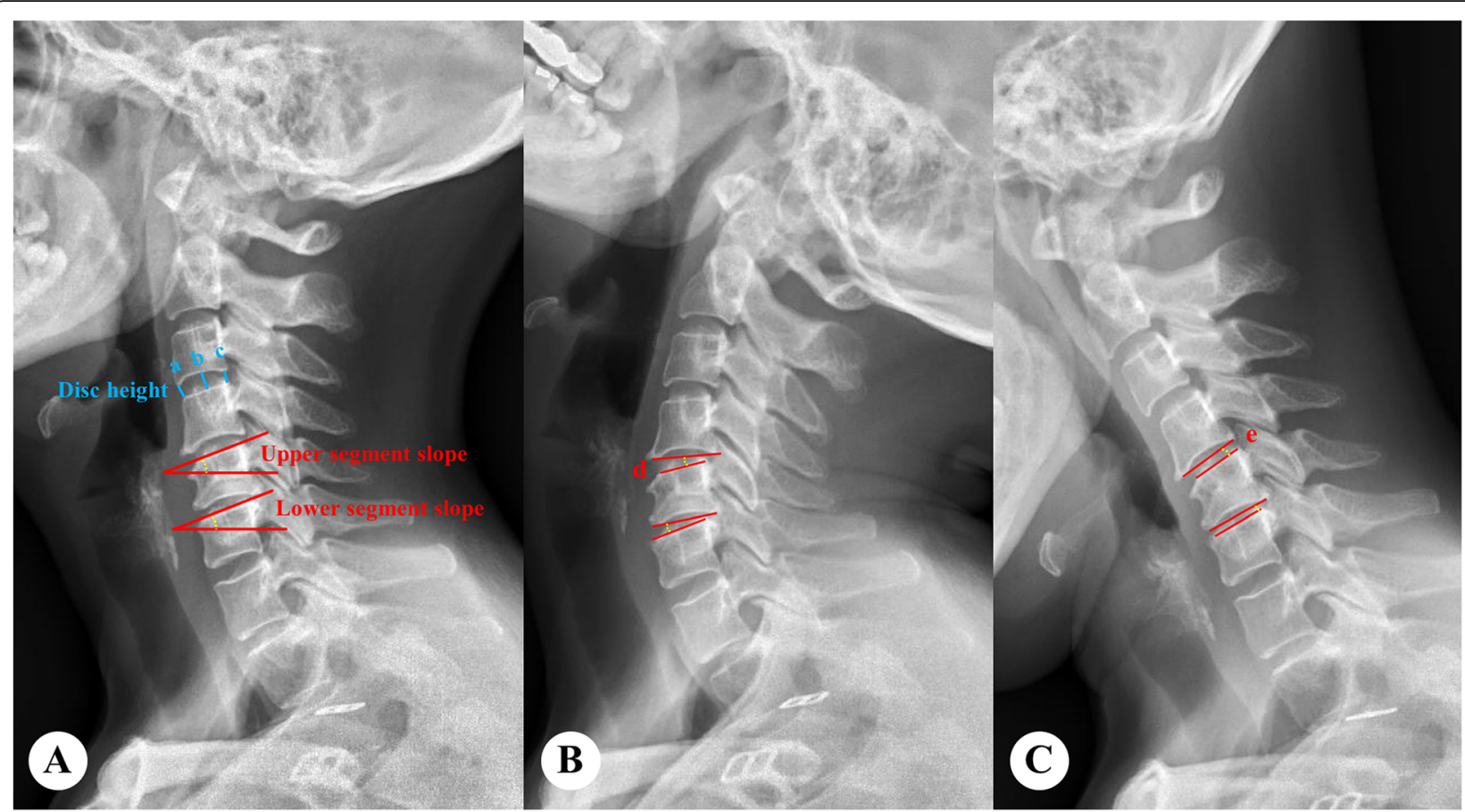

Fig. 1 A Disk height is calculated as $(a+b+c) / 3$. The segment slope is defined as the angle between the horizontal line and the extension line of the upper endplate of the middle (or caudal) vertebral body. B, C Range of motion is calculated as $\mathrm{d}$-e

NY, USA) was used to perform standard statistical analyses. A two-tailed $p$ value $<0.05$ was considered significant.

\section{Results}

\section{Patient demographics}

Eleven patients were excluded because three had tumors, two had tuberculosis infection, and six were lost to follow-up. In total, 118 patients and 236 fusion levels with at least 2-year follow-up were enrolled in this study, including 57 women and 61 men, with a mean age of 54.6 (range, 29-75) years. The mean duration of followup was 35.7 (range, 25-81) months. Detailed demographic data are summarized in Table 1.

\section{Fusion rate}

Among the 118 patients, 13 (11.01\%) underwent ACDF at the C3-C5 levels, 58 (49.15\%) at the C4-C6 levels, and $47(39.83 \%)$ at the C5-C7 levels. Overall, 106 (89.83\%) patients achieved two-level fusion at the last follow-up. Moreover, three (2.54\%) patients had only one-level fusion and nine (7.62\%) had two-level nonfusion. A significant difference was found in the fusion rates between the cranial and caudal levels at 3 and 6 months postoperatively (Fig. 2). In all patients with fusion at the caudal levels, fusion at the cranial levels had already been achieved at 3 months postoperatively. Only seven $(5.93 \%)$ patients had fusion at the caudal levels and non-fusion at the cranial levels at 6 months postoperatively. Interestingly, this difference disappeared at the 12-month and last follow-ups. Additionally, the nonfusion group had a larger preoperative segment slope than the fusion group. No significant difference was noted in the preoperative segment ROM and preoperative $\mathrm{DH}$ between the two groups (Table 2). Among the 236 levels, 13 (5.51\%) were at the C3/4 level, 71 (30.08\%) at the C4/5 level, 105 (44.49\%) at the C5/6 level, and 47 (19.92\%) at the C6/7 level. A total of 215 (91.1\%) levels achieved fusion at the last follow-up. The fusion rate differed between the distribution of the operative segments at 3, 6, and 12 months $(p<0.05)$ (Table 3). The C6/7

Table 1 Demographic information

\begin{tabular}{ll}
\hline & Variable \\
\hline Sex (female/male) & $57 / 61$ \\
Age (years) & $54.63 \pm 10.94$ \\
Follow-up time (month) & $35.7 \pm 11.22$ \\
BMI (kg/m ${ }^{2}$ ) & $23.89 \pm 4.21$ \\
Smoker (\%) & $39(33.06 \%)$ \\
Operative level (\%) & \\
C3/4, C4/5 & $13(11.02 \%)$ \\
C4/5, C5/6 & $58(49.15 \%)$ \\
C5/6, C6/7 & $47(39.83 \%)$ \\
\hline
\end{tabular}

$B M I$ body mass index

Data are presented mean \pm standard deviation or number (\%) 


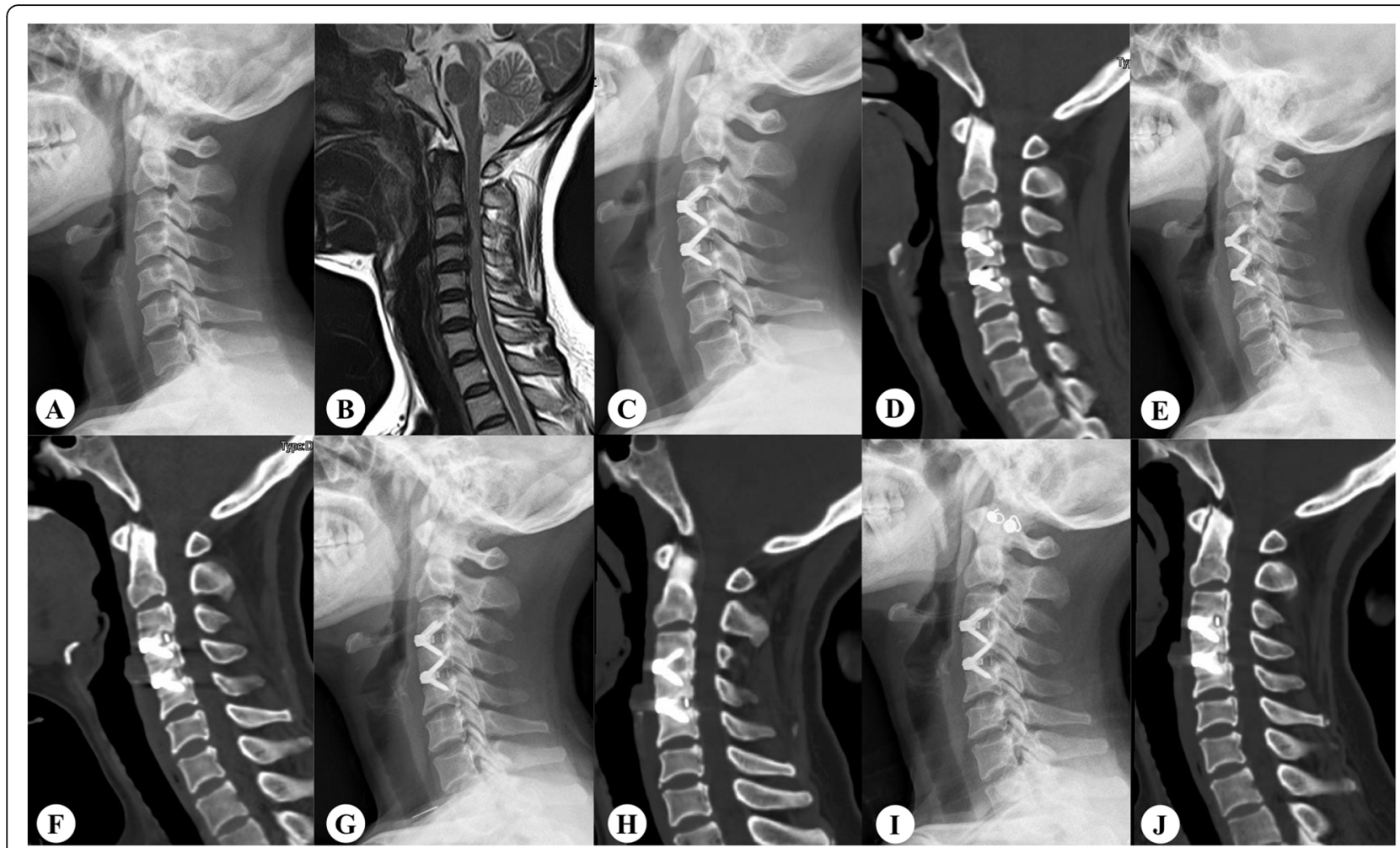

Fig. 2 Radiographs of a 49-year-old woman. A, B Preoperative lateral radiograph showing degeneration and compression at the C3/4 and C4/5 levels. C, D Postoperative image showing two suitable prostheses placed at those levels. E, F Three-month postoperative lateral radiograph showing a growing bridge only at the cranial level. G, H Fusion of only the cranial level at 6 months postoperatively. I, J At 2 years postoperatively, fusion of only the cranial level is complete

level accounted for the caudal fusion rate compared with the $\mathrm{C} 3 / 4$ and $\mathrm{C} 4 / 5$ levels (Bonferroni-adjusted, $p<$ $0.008)$ at 3 months postoperatively.

Logistic regression analysis was performed to confirm that both the relative position ( 3 months, $B=0.987$, odds ratio $[\mathrm{OR}]=2.684,95 \%$ confidence interval $[\mathrm{CI}]$ $1.075-6.698, p<0.05$; 6 months, $B=0.859$, OR $=2.362$, 95\% CI 1.192-4.687) and preoperative segments slope (3 months, $B=-0.100$, OR $=0.905,95 \%$ CI $0.840-0.976, p$ $<0.05 ; 6$ months, $\mathrm{B}=-0.101$, OR $=0.920,95 \% \mathrm{CI}$ 0.868-0.974, $p<0.001$ ) were predictive factors of fusion success. Segment distribution was not related with fusion success (Table 4).

\section{Complications}

Subsidence was detected in $22(9.32 \%)$ levels at the last follow-up. Radiographic ASD was detected in 55 (23.31\%) levels at the last follow-up. However, no patient required adjacent-segment secondary surgery during the follow-up. In addition, no significant difference concerning ASD or subsidence was observed between the cranial and caudal levels (Table 5). No screw loosening, displacement, vertebral body osteolysis, or vertebral fracture was reported in all patients. No patient required implant-related secondary surgery.

\section{Discussion}

Fusion is an important criterion to determine the success of ACDF. The criteria for judging whether fusion has been achieved have not been established yet [21], which affects the observed values of the fusion rate. After reviewing the literature, we believe that the criterion used in our study is accurate. In recent studies, the fusion rate of two-level ACDF ranged from 91.4 to 100\% [22-25], with at least 1 year of follow-up. However, the regularity of early postoperative fusion (3-6 months) is the key to accelerated rehabilitation. Unfortunately, there were few related studies on this topic. The results of the present study reveal the early fusion rule after two-level ACDF, which may provide a reference for adjusting the bone grafting strategy. Some bone chips or bone dust are often produced during decompression. These bone tissues can be transplanted back to the intervertebral space as an autograft to promote fusion. However, in two-level ACDF, these bones are often enough to fill only one intervertebral space. Thus, this study provides a reference for which intervertebral space should be filled.

The fusion rate of the cranial and caudal levels was different in two-level ACDF. Wang et al. [17] found that all pseudarthrosis in multi-level ACDF occurred at the 


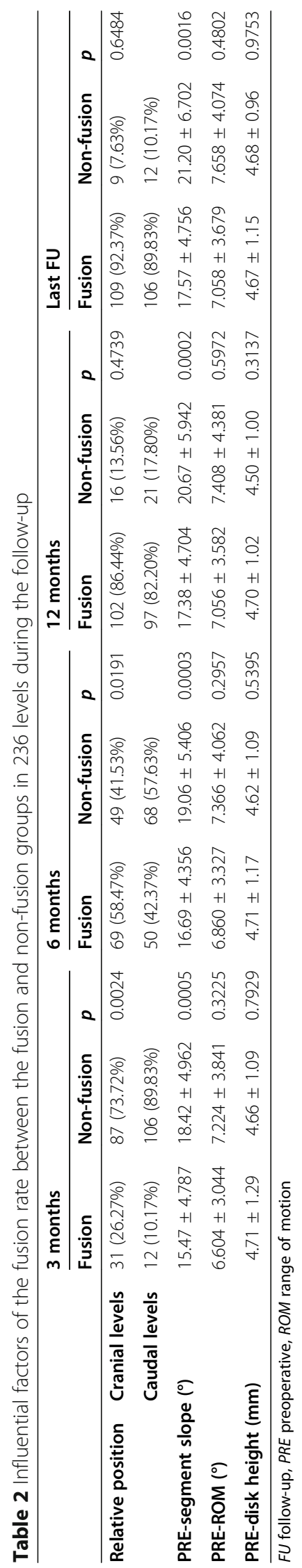




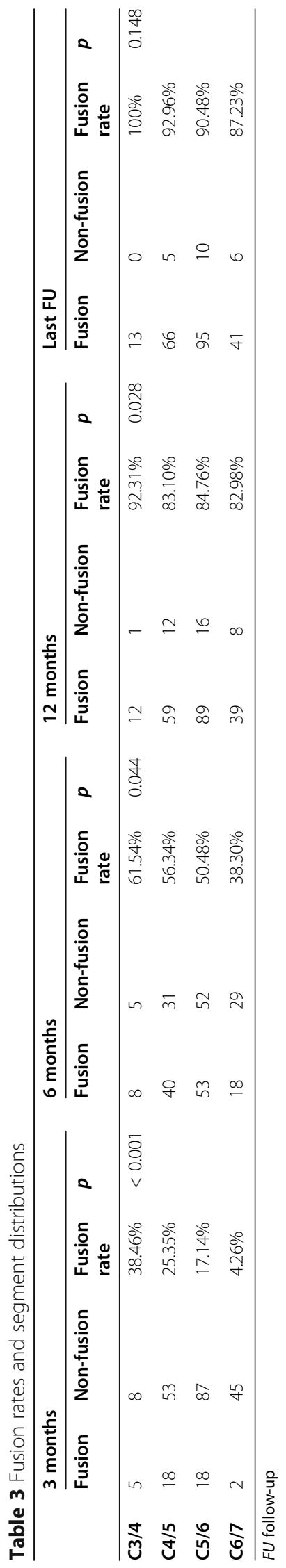


Table 4 Multivariate logistic regression analysis of the influential factors of the fusion rate

\begin{tabular}{|c|c|c|c|c|c|c|c|c|}
\hline & \multicolumn{4}{|c|}{3 months } & \multicolumn{4}{|c|}{6 months } \\
\hline & $\bar{B}$ & OR & $95 \% \mathrm{Cl}$ & $p$ & $\bar{B}$ & OR & $95 \% \mathrm{Cl}$ & $p$ \\
\hline Relative position & 0.987 & 2.684 & $1.075-6.698$ & 0.034 & 0.859 & 2.362 & $1.192-4.687$ & 0.014 \\
\hline Preoperative segment slope & -0.1 & 0.905 & $0.840-0.976$ & 0.009 & -0.101 & 0.904 & $0.852-0.959$ & 0.014 \\
\hline $\mathrm{C} 3 / 4$ & 1.073 & 2.924 & $0.359-23.788$ & 0.316 & -0.520 & 0.595 & $0.132-2.688$ & 0.500 \\
\hline $\mathrm{C} 4 / 5$ & 0.951 & 2.588 & $0.458-14.643$ & 0.282 & -0.398 & 0.671 & $0.255-1.770$ & 0.420 \\
\hline $\mathrm{C} 5 / 6$ & 0.860 & 2.362 & $0.466-11.971$ & 0.299 & 0.041 & 1.042 & $0.476-2.284$ & 0.918 \\
\hline $\mathrm{C} 6 / 7$ & - & 1 & - & - & - & 1 & - & - \\
\hline
\end{tabular}

$\mathrm{Cl}$ confidence interval, $\mathrm{OR}$ odds ratio

caudal level with an average follow-up of 3.2 years. Nichols et al. [18] also found that the fusion rate was lower at 24 months postoperatively in multi-level ACDF when using the plate with a cage system. McClure et al. [26] reported that only $44 \%$ and $42 \%$ of multi-level ACDFs achieved fusion at the C6-7 and C7-T1 levels, which was significantly lower than that for the C3-6 level. However, no study has compared the fusion rate between the cranial and caudal levels with the zeroprofile device in ACDF. Because of the high mobility of the cervical vertebra and stiffness of the thoracic vertebra, there is tremendous biomechanical pressure at the cervicothoracic junction, and this area is prone to degradation $[27,28]$. In two-level ACDF, the caudal segment is closer to the cervicothoracic junction, so the potential activity of the caudal segment was higher, which may be the reason for its caudal fusion rate. In addition, zero-profile fixation is less robust than plate fixation, which may lead to greater potential activity, resulting in a higher incidence of non-fusion. Through the preliminary analysis, we found that the fusion rate was related to the absolute and relative positions of the segments. To confirm the effect of these positions on the fusion rate and exclude confounding factors, we included these variables and the segment slope into the multivariate logistic regression analysis and found that the caudal level was an independent risk factor of nonfusion. A biomechanical study [29] reported that C6/7 is the first segment and the most active segment of the cervical spine to move during flexion and extension, and it moves much more than other segments, which means that it receives more force during cervical movement and reduces the fusion rate. Interestingly, no difference was noted in the rates of subsidence and incidence of ASD between the cranial and caudal segments.

The fusion rate may be related to the preoperative segment slope in two-level ACDF. The larger segment slope tends to mean larger shear stress. Other studies [16, 30, 31] have found that the preoperative T1 slope is a risk factor for non-fusion or pseudarthrosis. Although the T1 slope is a conventional base for describing cervical sagittal position force lines, it was not measurable in nearly $70 \%$ of the patients $[32,33]$. Certain differences were also noted in the slope of each segment, so the T1 slope cannot directly reflect the slope of the index level. Therefore, this study directly measured the slope of the two index levels and determined its relationship with the fusion rate.

This study has some limitations. First, this was a retrospective study, and there may be inherent potential bias. Second, the results of the 2-year follow-up might have underestimated the incidence of ASD. Thus, long-term follow-up studies are needed to confirm the incidence of ASD. Third, this study did not describe other possible risk factors for non-fusion. In this study, age, sex, smoking, osteoporosis, T1 slope, diabetes, and other confounding factors were well controlled by matching and comparing the fusion rates between the cranial and caudal segments. Thus, not all risk factors of non-fusion were elaborated and focused on in this study. Despite these limitations, to the best of our knowledge, this is the first study to focus on the fusion rate and order between the cranial and caudal levels in two-level ACDF in a large sample of patients. Moreover, this study provides us with more ideas on achieving early fusion.

Table 5 Comparison of complications between the cranial and caudal levels at the last follow-up

\begin{tabular}{llll}
\hline & Cranial levels & Caudal levels & $p$ \\
Subsidence (rate) & $10(8.47 \%)$ & $12(10.17 \%)$ & 0.824 \\
& Cranial adjacent segment & Caudal adjacent segment & 0.218 \\
\hline
\end{tabular}




\section{Conclusions}

The caudal level had a slower fusion process than the cranial level. A higher preoperative segment slope was a risk factor of fusion. However, the subsidence and ASD rate were comparable between the caudal and cranial levels in two-level ACDF.

\section{Abbreviations}

ACDF: Anterior cervical discectomy and fusion; ASD: Adjacent segment degeneration; BMI: Body mass index; CDDD: Cervical disk degenerative disease; Cl: Confidence interval; CT: Computed tomography; DH: Disk height; FU: Follow-up; MRI: Magnetic resonance imaging; OR: Odds ratio; ROM: Range of motion

\section{Acknowledgements}

We are very grateful to those who helped in the study process.

\section{Authors' contributions}

XQS and HL contributed to the design of the study. XQS drafted the manuscript with help from YM, BYW, and YY. XQS conducted the statistical analyses. Statistical analysis was discussed with YM, BYW, and HL. XQS, XR, and $\mathrm{YH}$ contributed to the revision. The authors have read and approved the final manuscript.

\section{Funding}

This study was supported by the 1.3.5 Project for Disciplines of Excellence, West China Hospital, Sichuan University (grant no. ZYJC18029 to Hao Liu), Postdoctor Research Project, West China Hospital, Sichuan University (grant no. 2018HXBH002 to Yang Meng), National Natural Science Foundation of China (grant no. 82002371 to Yi Yang), Sichuan Province Science and Technology Program of China (grant no. 18ZDYF2182 to Xin Rong), and the West China Nursing Discipline Development Special Fund Project (No. HXHL19016 to Ying Hong) of West China Hospital, Sichuan University. There were no relevant financial activities outside the submitted work.

\section{Availability of data and materials}

The datasets in this study are available from the corresponding author on reasonable request.

\section{Declarations}

\section{Ethics approval and consent to participate}

All participants provided signed, informed consent prior to study participation. This study was approved by the Ethics Committee on Biomedical Research, West China Hospital of Sichuan University (2019946) and was conducted following the 1964 Helsinki Declaration and its later amendments or comparable ethical standards.

\section{Consent for publication}

Not applicable.

\section{Competing interests}

The authors declare that they have no competing interests.

\section{Author details}

'Department of Orthopedic Surgery, West China Hospital, Sichuan University, No. 37 Guo Xue Xiang, Chengdu 610041, Sichuan, China. ${ }^{2}$ West China School of Nursing, Sichuan University, No. 37 Guo Xue Xiang, Chengdu 610041 Sichuan, China. ${ }^{3}$ Department of Anesthesia and Operation Center, West China Hospital, Sichuan University, No. 37 Guo Xue Xiang, Chengdu 610041 Sichuan, China.

Received: 25 June 2021 Accepted: 5 August 2021

Published online: 16 August 2021

\section{References}

1. Cloward RB. The anterior approach for removal of ruptured cervical disks. J Neurosurg. 1958;15(6):602-17. https://doi.org/10.3171/jns.1958.15.6.0602.
2. Smith GW, Robinson RA. The treatment of certain cervical-spine disorders by anterior removal of the intervertebral disc and interbody fusion. J Bone Joint Surg Am Vol. 1958;40-a(3):607-24.

3. Han YC, Liu ZQ, Wang SJ, Li LJ, Tan J. Is anterior cervical discectomy and fusion superior to corpectomy and fusion for treatment of multilevel cervical spondylotic myelopathy? A systemic review and meta-analysis. PLoS One. 2014;9(1):e87191. https://doi.org/10.1371/journal.pone.0087191.

4. Zhao Y, Yang S, Huo Y, Li Z, Yang D, Ding W. Locking stand-alone cage versus anterior plate construct in anterior cervical discectomy and fusion: a systematic review and meta-analysis based on randomized controlled trials. Eur Spine J. 2020;29(11):2734-44. https://doi.org/10.1007/s00586-020-06561$x$.

5. Sun Z, Liu Z, Hu W, Yang Y, Xiao X, Wang X. Zero-profile versus cage and plate in anterior cervical discectomy and fusion with a minimum 2 years of follow-up: a meta-analysis. World Neurosurg. 2018;120:e551-e61. https://doi. org/10.1016/j.wneu.2018.08.128.

6. Epstein NE. A review of complication rates for anterior cervical diskectomy and fusion (ACDF). Surg Neurol Int. 2019;10:100. https://doi.org/10.25259/ SNI-191-2019.

7. Pennington Z, Mehta VA, Lubelski D, Elliott C, Miller JA, Benzel EC, et al. Quality of life and cost implications of pseudarthrosis after anterior cervical discectomy and fusion and its subsequent revision surgery. World Neurosurg. 2020;133:e592-e9. https://doi.org/10.1016/j.wneu.2019.09.104.

8. van Eck CF, Regan C, Donaldson WF, Kang JD, Lee JY. The revision rate and occurrence of adjacent segment disease after anterior cervical discectomy and fusion: a study of 672 consecutive patients. Spine. 2014;39(26):2143-7. https://doi.org/10.1097/BRS.0000000000000636.

9. Mediouni M. D RS, Madry H, Cucchiarini M, Rai B. A review of translational medicine. The future paradigm: how can we connect the orthopedic dots better? Curr Med Res Opin. 2018;34(7):1217-29. https://doi.org/10.1080/03 007995.2017.1385450.

10. Noordhoek I, Koning MT, Vleggeert-Lankamp CLA. Evaluation of bony fusion after anterior cervical discectomy: a systematic literature review. Eur Spine J. 2019:28(2):386-99. https://doi.org/10.1007/s00586-018-5820-9.

11. Hilibrand AS, Fye MA, Emery SE, Palumbo MA, Bohlman HH. Impact of smoking on the outcome of anterior cervical arthrodesis with interbody or strut-grafting. J Bone Joint Surg Am Vol. 2001;83(5):668-73. https://doi.org/1 0.2106/00004623-200105000-00004

12. Purvis TE, Rodriguez HJ, Ahmed AK, Boone C, de la Garza-Ramos R, Elder $\mathrm{BD}$, et al. Impact of smoking on postoperative complications after anterior cervical discectomy and fusion. J Clin Neurosci. 2017;38:106-10. https://doi. org/10.1016/j.jocn.2016.12.044.

13. Phan K, Kim JS, Lee N, Kothari P, Cho SK. Impact of insulin dependence on perioperative outcomes following anterior cervical discectomy and fusion. Spine. 2017:42(7):456-64. https://doi.org/10.1097/BRS.0000000000001829.

14. Salzmann SN, Okano I, Ortiz Miller C, Chiapparelli E, Reisener MJ, Winter $F$, et al. Regional bone mineral density differences measured by quantitative computed tomography in patients undergoing anterior cervical spine surgery. Spine J. 2020;20(7):1056-64. https://doi.org/10.101 6/j.spinee.2020.02.011

15. Ren B, Gao W, An J, Wu M, Shen Y. Risk factors of cage nonunion after anterior cervical discectomy and fusion. Medicine. 2020;99(12):e19550. https://doi.org/10.1097/MD.0000000000019550.

16. Choi SH, Cho JH, Hwang CJ, Lee CS, Gwak HW, Lee DH. Preoperative radiographic parameters to predict a higher pseudarthrosis rate after anterior cervical discectomy and fusion. Spine. 2017;42(23):1772-8. https:// doi.org/10.1097/BRS.0000000000002219.

17. Wang JC, McDonough PW, Kanim LE, Endow KK, Delamarter RB. Increased fusion rates with cervical plating for three-level anterior cervical discectomy and fusion. Spine. 2001;26(6):643-6; discussion 6-7. https://doi.org/10.1097/ 00007632-200103150-00015.

18. Nichols NM, Jamieson A, Wang M, Chou D, Mummaneni PV, Tan LA Characterizing the fusion order and level-specific rates of arthrodesis in 3level anterior cervical discectomy and fusion: a radiographic study. J Clin Neurosci. 2020;81:328-33. https://doi.org/10.1016/j.jocn.2020.10.024.

19. Xiong W, Zhou J, Sun C, Chen Z, Guo X, Huo X, et al. 0.5- to 1-fold intervertebral distraction is a protective factor for adjacent segment degeneration in single-level anterior cervical discectomy and fusion. Spine. 2020;45(2):96-102. https://doi.org/10.1097/BRS.0000000000003209.

20. Phillips FM, Lee JY, Geisler FH, et al. A prospective, randomized, controlled clinical investigation comparing PCM cervical disc arthroplasty with anterior 
cervical discectomy and fusion. 2-year results from the US FDA IDE clinical trial. Spine. 2013;38(15):E907-18. https://doi.org/10.1097/BRS.0b013e3182 96232f.

21. Shriver MF, Lewis DJ, Kshettry VR, Rosenbaum BP, Benzel EC, Mroz TE. Pseudoarthrosis rates in anterior cervical discectomy and fusion: a metaanalysis. Spine J. 2015;15(9):2016-27. https://doi.org/10.1016/j.spinee.2015.05. 010 .

22. Moo IH, Kam CJW, Lai MWS, Yeo W, Soh RCC. A comparison of contiguous two-level anterior cervical discectomy and fusion using a structural allograft versus a polyetheretherketone (PEEK) cage: the results of a three-year follow-up. BMC Musculoskelet Disord. 2020;21(1):331. https://doi.org/10.11 86/s12891-020-03325-y.

23. Scholz M, Onal B, Schleicher P, Pingel A, Hoffmann C, Kandziora F. Two-level ACDF with a zero-profile stand-alone spacer compared to conventional plating: a prospective randomized single-center study. Eur Spine J. 2020; 29(11):2814-22. https://doi.org/10.1007/s00586-020-06454-z.

24. Yang S, Yu Y, Liu X, Zhang Z, Hou TY, Xu J, et al. Clinical and radiological results comparison of allograft and polyetheretherketone cage for one to two-level anterior cervical discectomy and fusion: a CONSORT-compliant article. Medicine. 2019;98(45):e17935. https://doi.org/10.1097/MD. 0000000000017935.

25. Park JS, Park SJ, Lee CS, Chung SS, Park HJ. Is allograft a more reliable treatment option than autograft in 2-level anterior cervical discectomy and fusion with plate fixation? Medicine. 2019;98(32):e16621. https://doi.org/10.1 097/MD.0000000000016621.

26. McClure JJ, Desai BD, Shabo LM, Buell TJ, Yen C-P, Smith JS, Shaffrey Cl, Shaffrey ME, Buchholz AL. A single-center retrospective analysis of 3- or 4level anterior cervical discectomy and fusion: surgical outcomes in 66 patients. J Neurosurg Spine. 2021;34(1):45-51. https://doi.org/10.3171/2020.6. SPINE20171.

27. Wang VY, Chou D. The cervicothoracic junction. Neurosurg Clin North Am. 2007;18(2):365-71. https://doi.org/10.1016/j.nec.2007.02.012.

28. Godzik J, Dalton JF, Martinez-Del-Campo E, Newcomb AGUS, Dominguez F, Reyes PM, Theodore N, Kelly BP, Crawford NR. Biomechanical evaluation of cervicothoracic junction fusion constructs. World Neurosurg. 2019;124:e13946. https://doi.org/10.1016/j.wneu.2018.12.040. https://www.sciencedirect. com/science/article/pii/S1878875018328638, ISSN 1878-8750.

29. Bogduk N, Mercer S. Biomechanics of the cervical spine. I: Normal kinematics. Clin Biomech (Bristol, Avon). 2000;15(9):633-48.

30. Weng C, Wang J, Tuchman A, Wang J, Fu C, Hsieh PC, et al. Influence of T slope on the cervical sagittal balance in degenerative cervical spine: an analysis using kinematic MRI. Spine. 2016;41(3):185-90. https://doi.org/10.1 097/BRS.00000000000001353.

31. Knott PT, Mardjetko SM, Techy F. The use of the T1 sagittal angle in predicting overall sagittal balance of the spine. Spine J. 2010;10(11):994-8. https://doi.org/10.1016/j.spinee.2010.08.031.

32. Tamai K, Buser Z, Paholpak P, Sessumpun K, Nakamura H, Wang JC. Can C7 slope substitute the T1 slope?: an analysis using cervical radiographs and kinematic MRIs. Spine. 2018;43(7):520-5. https://doi.org/10.1097/BRS. 0000000000002371.

33. Ye IB, Tang R, Cheung ZB, White SJW, Cho SK. Can C7 slope be used as a substitute for T1 slope? A radiographic analysis. Glob Spine J. 2020;10(2): 148-52. https://doi.org/10.1177/2192568219846909.

\section{Publisher's Note}

Springer Nature remains neutral with regard to jurisdictional claims in published maps and institutional affiliations.

Ready to submit your research? Choose BMC and benefit from:

- fast, convenient online submission

- thorough peer review by experienced researchers in your field

- rapid publication on acceptance

- support for research data, including large and complex data types

- gold Open Access which fosters wider collaboration and increased citations

- maximum visibility for your research: over $100 \mathrm{M}$ website views per year

At BMC, research is always in progress.

Learn more biomedcentral.com/submissions 